\title{
Immediate Effects of Roller Massage for Posterior Neck Muscles on the Muscle Strength and Range of Motion for Cranio-Cervical Flexion in Subjects With Forward Head Posture
}

\author{
Seung-tak Kang ${ }^{1}$, BPT, PT, Jang-hun Jung², BPT, PT, Oh-yun Kwon³, PhD, PT \\ ${ }^{1}$ Department of Physical and Rehabilitation Medicine, Samsung Medical Center, Sungkyunkwan University School of Medicine, ${ }^{2}$ Department \\ of Physical and Rehabilitation Medicine, Kyung Hee University Medical Center, Seoul, ${ }^{3}$ Department of Physical Therapy, College of Health \\ Science, Laboratory of Kinetic Ergocise Based on Movement Analysis, Yonsei University, Wonju, Korea
}

\author{
Article Info \\ Received January 5, 2021 \\ Revised January 19, 2021 \\ Accepted February 24, 2021 \\ Corresponding Author \\ Oh-yun Kwon \\ E-mail: kwonoy@yonsei.ac.kr \\ https://orcid.org/0000-0002-9699-768X
}

\section{Key Words}

Cranio-cervical flexion

Forward head posture

Roller massage

Suboccipital release
Background: Forward head posture (FHP) causes various posture imbalances associated with the head and neck. Myofascial release is an effective treatment method used for relaxing muscles and reducing muscle hyperactivity, but no studies have been conducted on suboccipital and neck muscles related to FHP.

Objects: The purpose of this study was to investigate the immediate effect of roller massages on the cranio-cervical flexion (CCF) range of motion (ROM) and CCF strength applied to suboccipital and neck muscles in subject with forward head posture.

Methods: Twenty-four FHP subjects (male: 13, female: 11) were recruited for this study. All subjects were recruited with a craniovertebral angle (CVA) of 53 degrees or less and a head tilt angle (HTA) of 20.66 degrees or higher. CCF strength was measured using Pressure biofeedback unit (PBU) in the supine posture and CCF ROM was measured using smartphone-based inclinometer. Roller massage (RM) was applied to suboccipital and neck muscles for 2 minutes and CCF ROM and strength were remeasured.

Results: These results of this study showed that CCF ROM was a significant difference in CCF ROM before and after RM $(p<0.05)$. CCF strength also showed a significant difference before and after RM $(p<0.05)$.

Conclusion: RM method might be recommended to increase the immediate ROM and strength of CCF in subjects with forward head posture.

\section{INTRODUCTION}

The forward head posture (FHP) comprises extension of the upper cervical region and flexion of the lower cervical region [1]. In FHP, an individual's head is in front of a vertical line passing through their center of gravity [2]. The FHP is the most common type of abnormal head posture associated with chronic neck pain; $60 \%$ of neck and shoulder pain patients report frequently assuming the FHP [3-5]. FHP leads to lengthening and weakness of the anterior cervical muscle and shortening of the posterior cervical part [2]. FHP is commonly associated with shortening of the suboccipital muscles such as the rectus capitis posterior major, minor, oblique capitis superior, inferior, and posterior neck muscles such as the upper trapezius, semispinalis capitis, cervicis, splenius capitis, and cervicis [6]. Changes in the neck posture also lead to abnormal cervical movements, which in turn leads to muscle imbalance [7]. Due to this, FHP causes pain in the neck and dysfunction of the muscular skeletal system [8].

Previous studies have shown that a decrease in the craniovertebral angle (CVA) is associated with an increase in FHP [9]. The cranio-cervical flexion (CCF) muscle plays an important role in straightening and supporting the cervical spine [10]. The CCF muscles such as the longus colli and longus capitis provide stability to and help control the position of the cervical vertebrae $[11,12]$.

Myofascial release is an effective therapy traditionally used for pain relief and relaxation of tensioned muscles [13]. Suboc- 
cipital release reduces tension in the deep upper cervical tissues and plays an important role in the cranio-cervical region [14]. Suboccipital release is reported to reduce the tightness and hyperactivity of the CCF muscle caused by FHP [15]. The mechanism of this change is as follows: it is believed that the Suboccipital release technique may help to relieve central sensitization by relaxing the upper cervical tissue [14]. Recently, self-myofascial release has been widely used in rehabilitation to improve myofascial mobility [16].

In physical therapists, wrist, hand, and finger pain is mostly related to their work [17]. More than 20\% of physical therapists experience wrist and hand injuries, which limits their ability to perform manual therapy techniques [18]. Therefore, treatment tools are being developed that can protect the wrists and hand of physical therapists and provide effective treatment for patients. Common self-myofascial release tools include foam rollers and a variety of roller massage (RM) tools [19]. According to a systematic review published in 2015, the use of foam rollers and RM are effective interventions that increase the range of motion ( $\mathrm{ROM}$ ) and improve muscle performance before and after exercise [20]. RM is widely used for the knees, hips, and ankles; however, to the best of our knowledge, there are no studies regarding its effect on the suboccipital and neck muscles, especially in subjects with FHP [20].

The purpose of this study was therefore to investigate the immediate effects of RM on CCF ROM and strength in subjects with FHP.

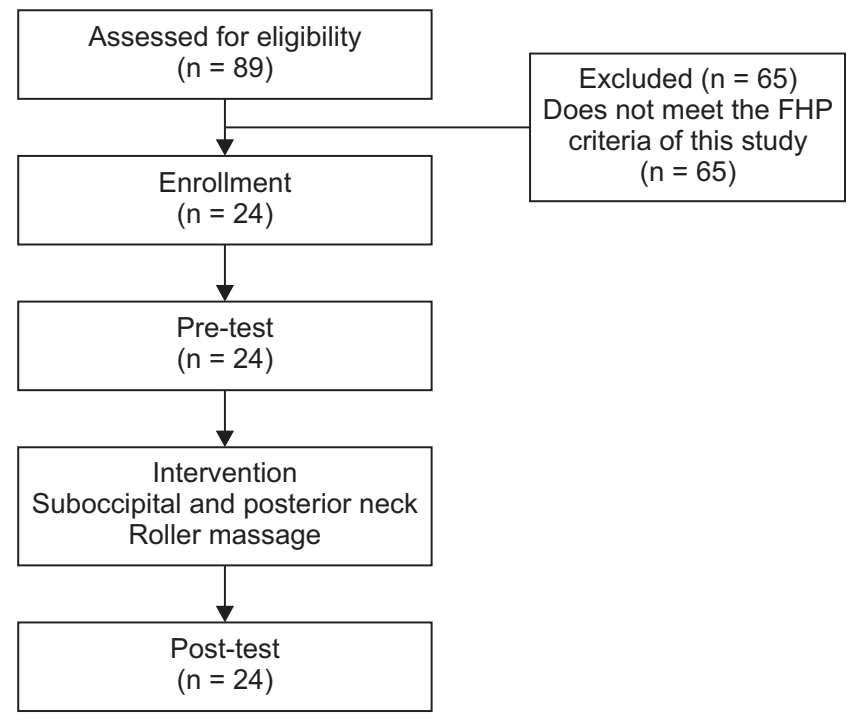

Figure 1. Diagram of the study. FHP, forward head posture.

\section{MATERIALS AND METHODS}

\section{Subjects}

A total of 24 subjects with FHP (13 male and 11 female) were recruited (Figure 1). FHP was defined as CVA $<53$ degrees [21] and head tilt angle (HTA) >20.66 degrees [22]. The inclusion criteria were: patients with FHP, who agreed to fully understand the experiment and participate voluntarily. The exclusion criteria were: neurological findings, surgical history [23], regular medication or treatment to alleviate recent pain, acute neck pain [24], and sphagiasmus or temporomandibular joint disability [25]. Before beginning data collection, the experimental protocol was explained to all subjects by the principal investigator, and participants signed an informed consent form approved by the Yonsei University Wonju Institutional Review Board (approval number: 1041849-202012-BM-181-05).

\section{Instruments}

An RM tool was used as an intervention to stretch the suboccipital and posterior neck muscles (RF-AC1929B-W; MTG Inc., Nagoya, Japan) (Figure 2). The RM tool consists of two round rollers and a streamlined handle. Holding the handle and moving forward and backward, the two rollers roll and stimulate the area.

A pressure biofeedback unit (PBU) is a device that sensitively measures pressure increase due to cervical nod (Stabilizer ${ }^{\mathrm{TM}}$; Chattanooga Group Inc., Hixson, TN, USA) (Figure 3). The PBU is a pressure transducer composed of a catheter, a sphygmo-

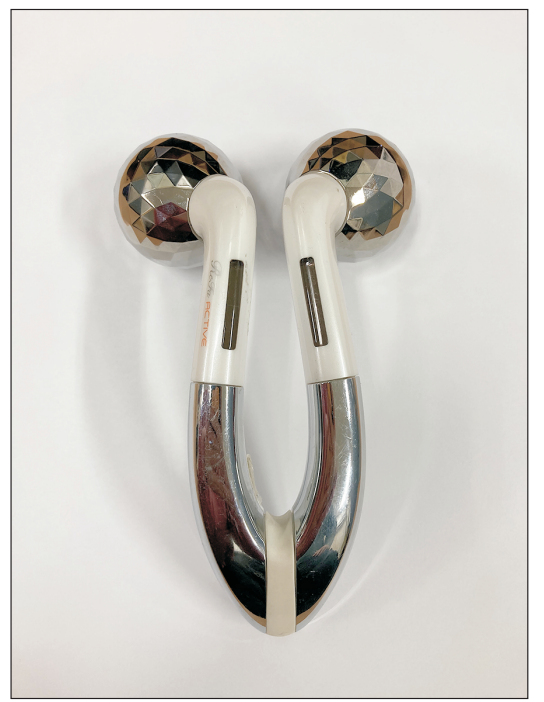

Figure 2. RF-AC1929B-W (MTG Inc.), tools for roller massage. 


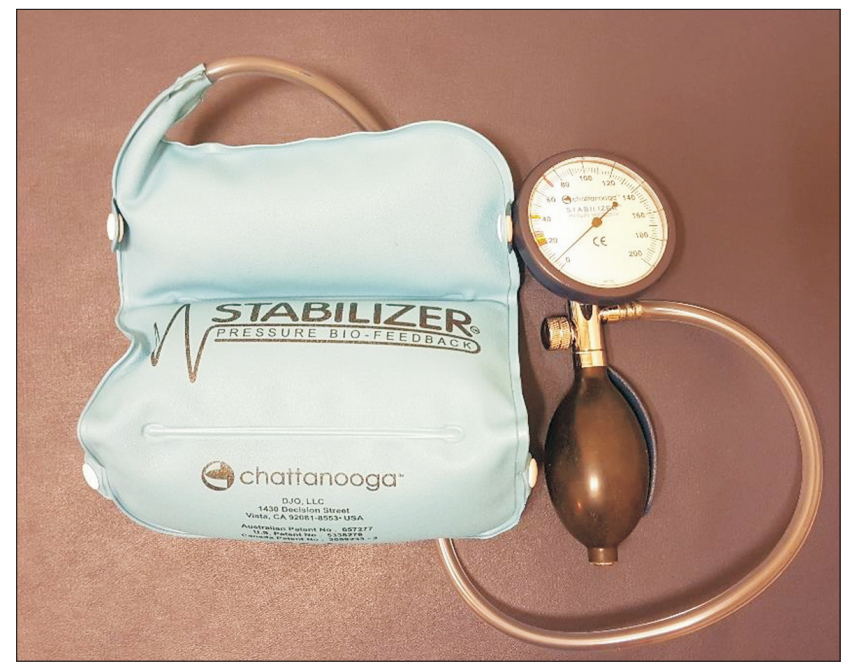

Figure 3. Stabilizer ${ }^{\top \mathrm{M}}$ (Chattanooga Group Inc.), the pressure biofeedback unit (PBU).

manometer, and a pressure bag consisting of three chambers. The pressure bag is made of an inelastic material. The range of the sphygmomanometer ranges from $0 \mathrm{mmHg}$ to $200 \mathrm{mmHg}$, with a gap of $2 \mathrm{mmHg}$ on the scale [26]. A change in the volume of the device pressure bag occurs due to movement or repositioning of the site using the PBU. It is visually displayed through a pressure gauge whether the muscles are used in the right way in the correct posture when performing a specific operation.

\section{Procedure}

All subjects were pre-tested for FHP, and RM was performed for 2 minutes when the subject criteria were confirmed. All subjects underwent measurement of the PBU pressure and CCF ROM before and after RM. The subject flexed the knee (hips $45^{\circ}$ flexion, knees $90^{\circ}$ flexion) in the supine position and pressure was applied using PBU on one hand. The RM intervention was applied to the subject's suboccipital and posterior neck for 2 minutes with no sets [27]. The sitting subjects performed full flexion of the neck, the principal investigator was standing behind the subject, and the suboccipital and posterior neck was massaged vertically using a RM. To investigate the effect of RM intervention, we measured changes in PBU pressure and CCF ROM before and after the massage.

\section{1) Craniovertebral angle}

Principal investigator attached markers to both. One is the spinous process of $\mathrm{C} 7$, and the other is an external auditory

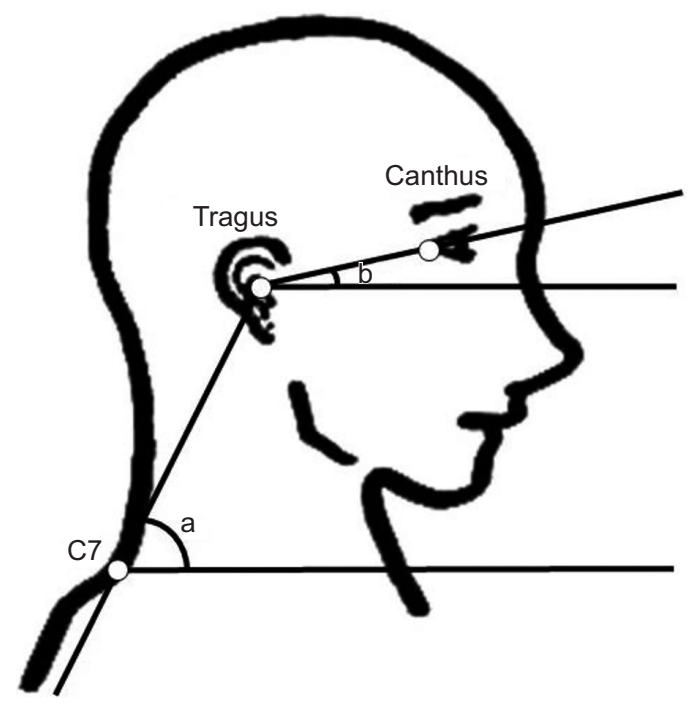

Figure 4. Adhesive marker placement and postural angles. a, craniocervical angle; $b$, head tilt angle.

meatus [28]. The CVA was measured as the angle between the line between C7 and the external auditory meatus and the horizontal line passing through C7 (Figure 4) [9]. When assessed clinically, FHP is determined by the CVA, with a smaller CVA indicating greater FHP [9].

\section{2) Head tilt angle}

The head tilt angle (HTA) is the angle that is used to evaluate the head tilt and represents the upper cervical flexion or extension position. A greater HTA indicates an extension of the head relative to the cervical spine [29]. The HTA is formed with the external canthus and tragus and the horizontal line passing through the tragus (Figure 4) [30].

\section{3) Cranio-cervical flexion range of motion}

We used a measurement tool equipped with a smartphonebased inclinometer (Figures 5, 6). With the patient in the supine posture, the forehead and chin were leveled using handmade smartphone-based measurement tools [31]. The CCF ROM was measured based on the horizontal state.

\section{4) PBU pressure}

Two PBUs were used for the subjects when measuring pressure. One was located in the upper cervical region. The upper cervical PBU measured pressure. Another PBU was placed in the lower cervical region. Lower cervical PBU observed the upper and lower thoracic movements. In the measurement, the 


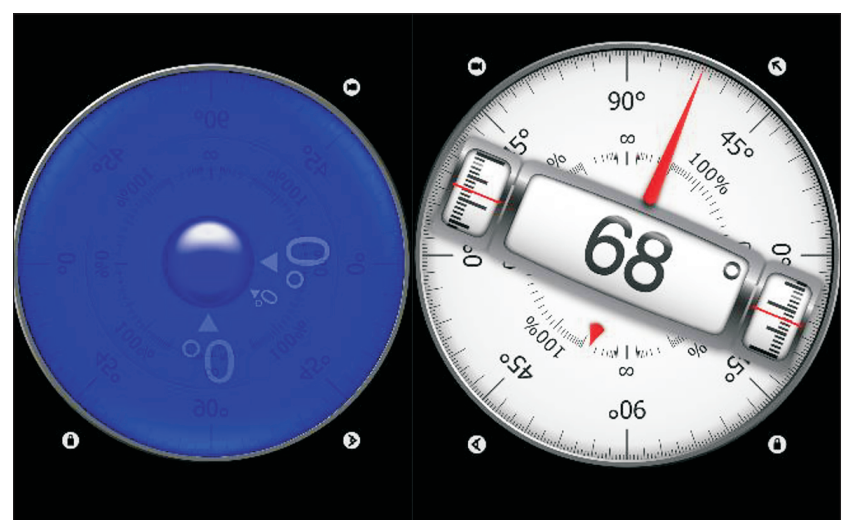

Figure 5. Smartphone-based inclinometer (horizontal and vertical).

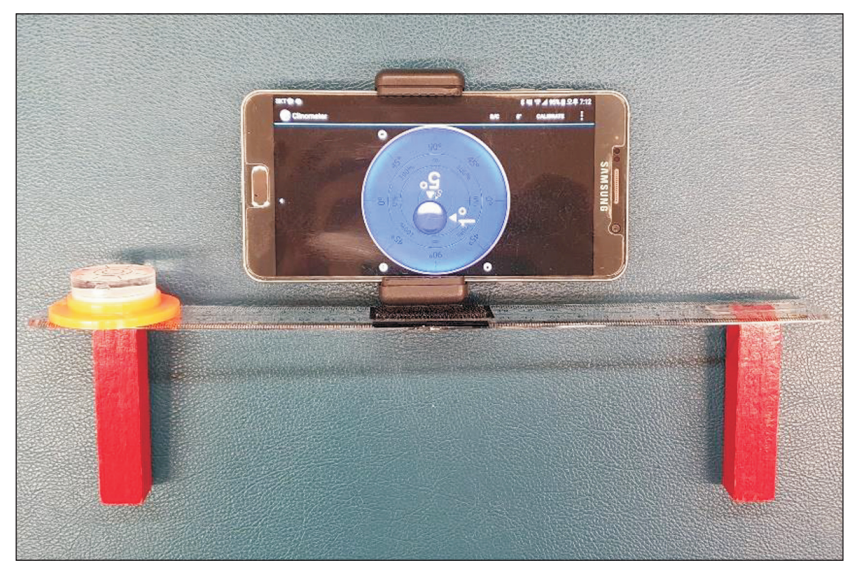

Figure 6. Hand-made smartphone-based measurement tools.

lower cervical PBU was maintained at $40 \mathrm{mmHg}$. A PBU was used to measure the pressures of both. To measure the pressure of the CCF, CCF tests using PBU were performed. The pressure was the maximum pressure applied at a base pressure of $80 \mathrm{mmHg}$. The maximum voluntary contractile strength of the subjects was measured [32].

Image J imaging software (U.S. National Institutes of Health, Maryland, USA) was used to measure CVA and HTA. The digital camera was placed perpendicular to the ground, with its lens $80 \mathrm{~cm}$ from the lateral aspect of the subject and pointing directly at the subject's shoulder to minimize parallax error [28]. The subject sat on the stool placed in the reference area, assuming a natural and relaxed position. The subject was asked to put both feet on the ground and to place the hands on the thighs while relaxing the back. Next, the principal investigator instructed the subject to fix their gaze on the point marked on the wall directly ahead.
Table 1. Baseline demographic and clinical characteristics ( $N=24)$

\begin{tabular}{lc}
\hline Baseline characteristic & Data \\
\hline Demographic characteristics & \\
Age $(\mathrm{y})$ & $24.09 \pm 2.334$ \\
Height $(\mathrm{cm})$ & $170.74 \pm 7.533$ \\
Weight $(\mathrm{kg})$ & $64.96 \pm 16.397$ \\
Sex & \\
Male & $13(54.2)$ \\
Female & $11(45.8)$ \\
Clinical characteristics & \\
CVA $\left.l^{\circ}\right)$ & $43.97 \pm 3.688$ \\
HTA $\left.l^{\circ}\right)$ & $26.23 \pm 3.284$
\end{tabular}

Values are presented as number (\%) or mean \pm standard deviation. CVA, craniovertebral angle; HTA, head tilt angle. FHP satisfied CVA lesser than 53 degrees and HTA greater than $20.66^{\circ}$.

\section{Statistical Analysis}

Statistical analyses were conducted using SPSS ver. 21.0 (SPSS Inc., Armonk, NY, USA). One-sample Kolmogorov-Smirnov test was used to confirm the assumption of normal distribution. The difference in PBU and CCF ROM data according to the two methods was compared using a paired t-test. The level of statistical significance $(\alpha)$ was set at 0.05 .

\section{RESULTS}

The general characteristics of subjects are presented in Table 1.

\section{Changes in Cranio-Cervical Flexion Angle}

CCF ROM was $8.82 \pm 4.22$ degrees before RM and $11.82 \pm$ 5.06 degrees after RM. There was a significant difference in the CCF ROM ( $p=0.002)($ Figure 7$)$.

\section{Changes in PBU Pressure of Cranio-Cervical Flexion}

PBU pressure was $87.82 \pm 4.36 \mathrm{mmHg}$ and after RM was $90.43 \pm 5.84 \mathrm{mmHg}$. There was a significant difference in the PBU pressure $(p=0.006)$ (Figure 8 ).

\section{DISCUSSION}

We investigated changes in the CCF ROM and strength after performing RM using a roller to perform suboccipital and posterior neck muscle release in FHP patients. The study showed significant increases in CCF ROM and strength.

Fascia restriction of the suboccipital region may limit the normal movement of the muscles located in different direc- 


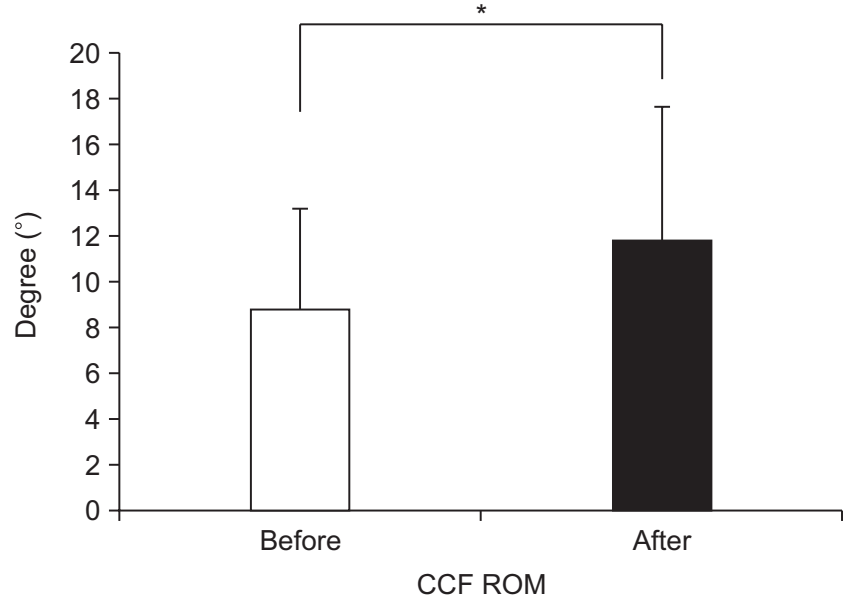

Figure 7. CCF ROM comparison before and after the RM. CCF, craniocervical flexion; ROM, range of motion; RM, roller massage. ${ }^{*} p<0.05$.

tions [33]. FHP generally leads to a shortening effect of the suboccipital extensors. Most of the suboccipital muscles (rectus capitis posterior major, minor, oblique capitis superior, inferior) and longissimus capitis, semispinalis capitis, splenius capitis, sternocleidomastoid, and upper fibers of the trapezius, were shortened by an average of $6.1 \%$ in FHP compared to the neutral head posture. The resulting body imbalance causes abnormal stress on other parts of the body due to fascia continuity.

The immediate and significant improvement in the ROM can be explained by several mechanisms. First, the ROM increases because of the increase in tissue compliance due to changes in the fascia stimulation trigger point and viscoelastic characteristics of tissues and tissue adhesion after applying RM [20,34]. The second mechanism is increased flexibility of the suboccipital muscles after RM. The third mechanism involves metabolic reactions with heat generation. RM induces low-lowintensity friction on the skin. Low-intensity friction between the surface of RM and skin generates heat as metabolic reactions. Increased heat leads to ROM improvement due to viscoelasticity of the connective tissue and muscles [35]. Jeong et al. [36] reported that soft tissue relaxation in the posterior upper cervical region and an increase in deep flexor muscle activity increase the movement of the cervical spine. Moreover, it helps to restore the normal flexibility of the posterior cervical muscles and is reestablished into normal cervical ROM. They reported that cervical flexion using CROM increased by $17 \%$ after suboccipital relaxation [36].

Bradbury-Squires et al. reported that the self-myofascial

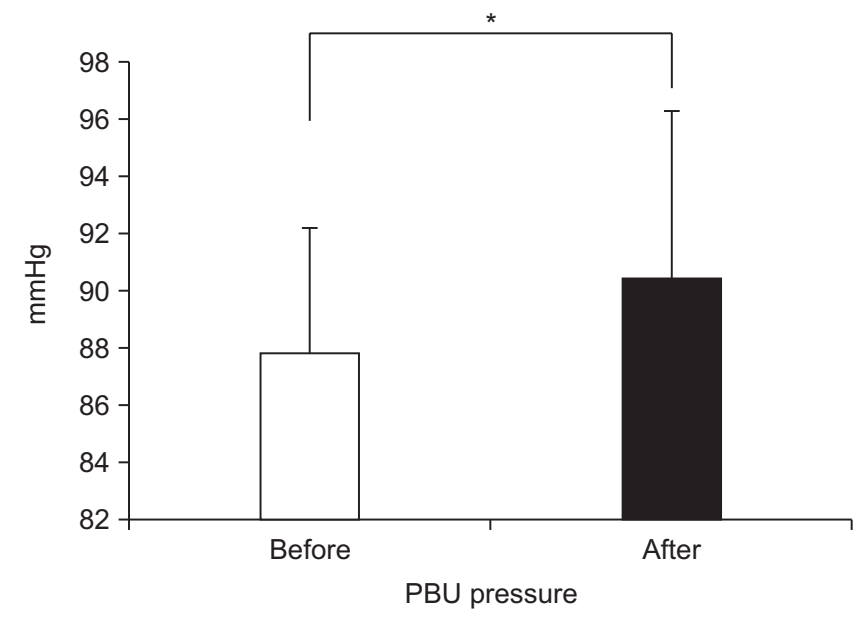

Figure 8. PBU pressure comparison before and after roller massage. PBU, pressure biofeedback unit. ${ }^{*} p<0.05$.

release of the suboccipital muscle showed significant improvements in the left rotation and overall technical ROM of the head. Bradbury-Squires et al. applied an RM to the knee joint for 20 and 60 seconds. Bradbury-Squires et al. reported that knee joint ROM increased by $10 \%$ and $16 \%$ at 20 and 60 seconds, respectively, when compared to the control group [35]. Monteiro et al. [37] conducted roller-massager to the hamstring to measure the ROM change of the hip extension. As a result of performing RM for 60 seconds, the hip extension angle increased by $135 \%$. In addition, when RM was performed for 120 seconds, the hip flexion angle increased by 21\% [37]. Halperin et al. [38] conducted a study to apply RM to plantar flexors. According to this, RM has an effect on ankle ROM and has a large effect when applied with static stretching [38]. In Heredia's study, Suboccipital release significantly improved head position by significantly increasing the CVA of subjects with FHP [14].

Studies on muscle strength and muscle performance have produced a variety of results. Halperin et al. [38] showed a significantly greater force when RM and static stretching were performed together than static stretching (8.2\%). Vastus lateralis RMS EMG was 3\% and 7\% less, respectively, with 20- and 60-second RMs, respectively, than the control conditions. In addition, the VL RMS EMG was approximately $4 \%$ less than that for 20 second with a 60-second RM [38]. Grabow et al. [39] improved knee flexion ROM without reducing strength and jump performance after quadriceps roller massage. Healey et al. [40] measured the isometric force after RM. There were no effects on performance in this study. After RM, the isokinetic knee ex- 
tension was measured at $90^{\circ} / \mathrm{s}$. No improvement was observed immediately after applying the RM [27].

Several researchers have suggested mechanisms for muscle strength production. A study has shown that increased muscle strength is associated with increased muscle temperature [41], and some studies show that the fascia limitation of the muscles is released [42]. In addition, some studies have reported that phosphorylation of myosin regulatory light chains is a factor, but additional studies are needed [43]. According to the general upper crossed syndrome, cranio-cervical flexor muscle weakening and suboccipital myofascial stiffness occur simultaneously [44]. As the stiffness of the suboccipital myofascial structures decreases the strength of the CCF, releasing the suboccipital structures may be a way to improve the strength of the deep cervical flexors [45].

Physical therapists often experience work-related musculoskeletal disorders in the course of their job performance. Because of this, $70 \%$ of physical therapists visit the hospital [46]. Work-related musculoskeletal disorders due to performing manual orthopedic techniques is reported to be experienced by $67.8 \%$ of physical therapists [47]. Various methods should be devised to prevent such physical therapist injuries. Physical therapy techniques using tools such as RM will be a good alternative to effectively relax the fascia while preventing hand and finger injury and pain.

There are some limitations to consider in this study. First, other studies have reported that musculotendinous stiffness returns to baseline after 30 minutes to 1 hour. Therefore, in the future, the same content should be applied in the long term to determine the effectiveness of RM. Second, we recruited subjects aged 20 years. Due to their limited age group, it is difficult to generalize to other populations. Finally, there was no control group that can be compared with RM, so it was difficult to clarify the intervention effect of this study.

\section{CONCLUSIONS}

In this study, we examined the immediate CCF ROM and strength changes when applying RM to subjects with FHP. Immediately after application of RM to the suboccipital and posterior neck in subjects with FHP, CCF maximum muscle strength and CCF ROM were increased. The results of this study suggest that RM can be applied as an alternative method for improving CCF ROM and strength in subjects with FHP.

\section{CONFLICTS OF INTEREST}

No potential conflict of interest relevant to this article was reported.

\section{AUTHOR CONTRIBUTIONS}

Conceptualization: SK, JJ, OK. Data curation: SK, JJ, OK. Formal analysis: SK, JJ, OK. Investigation: SK, JJ, OK. Methodology: SK, JJ, OK. Project administration: SK, JJ, OK. Resources: SK, JJ, OK. Software: SK, JJ, OK. Supervision: SK, JJ, OK. Validation: SK, JJ, OK. Visualization: SK, JJ, OK. Writing - original draft: SK, JJ, OK. Writing - review \& editing: SK, JJ, OK.

\section{ORCID}

Seung-tak Kang, https://orcid.org/0000-0002-6019-9635

Jang-hun Jung, https://orcid.org/0000-0002-3880-4552

\section{REFERENCES}

1. Iqbal ZA, Rajan R, Khan SA, Alghadir AH. Effect of deep cervical flexor muscles training using pressure biofeedback on pain and disability of school teachers with neck pain. J Phys Ther Sci 2013;25(6):657-61.

2. Lee MY, Lee HY, Yong MS. Characteristics of cervical position sense in subjects with forward head posture. J Phys Ther Sci 2014;26(11):1741-3.

3. Chiu TW, Lau KT, Ho CW, Ma MC, Yeung TF, Cheung PM. A study on the prevalence of and risk factors for neck pain in secondary school teachers. Public Health 2006;120(6):563-5.

4. Szeto GP, Straker L, Raine S. A field comparison of neck and shoulder postures in symptomatic and asymptomatic office workers. Appl Ergon 2002;33(1):75-84.

5. Yip CH, Chiu TT, Poon AT. The relationship between head posture and severity and disability of patients with neck pain. Man Ther 2008;13(2):148-54.

6. Singla D, Veqar Z. Association between forward head, rounded shoulders, and increased thoracic kyphosis: a review of the literature. J Chiropr Med 2017;16(3):220-9.

7. Yoo WG, An DH. The relationship between the active cervical range of motion and changes in head and neck posture after continuous VDT work. Ind Health 2009;47(2):183-8. 
8. Raine S, Twomey LT. Head and shoulder posture variations in 160 asymptomatic women and men. Arch Phys Med Rehabil 1997;78(11):1215-23.

9. Quek J, Pua YH, Clark RA, Bryant AL. Effects of thoracic kyphosis and forward head posture on cervical range of motion in older adults. Man Ther 2013;18:65-71.

10. Gupta BD, Aggarwal S, Gupta B, Gupta M, Gupta N. Effect of deep cervical flexor training vs. conventional isometric training on forward head posture, pain, neck disability index in dentists suffering from chronic neck pain. J Clin Diagn Res 2013;7(10):2261-4

11. Falla D, Jull G, O'Leary S, Dall'Alba P. Further evaluation of an EMG technique for assessment of the deep cervical flexor muscles. J Electromyogr Kinesiol 2006;16(6):621-8.

12. Jun I, Kim K. A comparison of the deep cervical flexor muscle thicknesses in subjects with and without neck pain during craniocervical flexion exercises. J Phys Ther Sci 2013;25(11):1373-5.

13. Ajimsha MS. Effectiveness of direct vs indirect technique myofascial release in the management of tension-type headache. J Bodyw Mov Ther 2011;15(4):431-5.

14. Heredia Rizo AM, Pascual-Vaca ÁO, Cabello MA, Blanco CR, Pozo FP, Carrasco AL. Immediate effects of the suboccipital muscle inhibition technique in craniocervical posture and greater occipital nerve mechanosensitivity in subjects with a history of orthodontia use: a randomized trial. J Manipulative Physiol Ther 2012;35(6):446-53.

15. Heintz MM, Hegedus EJ. Multimodal management of mechanical neck pain using a treatment based classification system. J Man Manip Ther 2008;16(4):217-24.

16. Cheatham SW, Kolber MJ, Cain M, Lee M. The effects of selfmyofascial release using a foam roll or roller massager on joint range of motion, muscle recovery, and performance: a systematic review. Int J Sports Phys Ther 2015;10(6):827-38.

17. Vieira ER, Svoboda S, Belniak A, Brunt D, Rose-St Prix C, Roberts L, et al. Work-related musculoskeletal disorders among physical therapists: an online survey. Disabil Rehabil 2016;38(6):552-7.

18. Alnaser MZ, Aljadi SH. Physical therapists with work-related musculoskeletal disorders in the State of Kuwait: a comparison across countries and health care professions. Work 2019;63(2):261-8

19. Pérez-Martínez C, Gogorza-Arroitaonandia K, Heredia-Rizo AM, Salas-González J, Oliva-Pascual-Vaca Á. INYBI: a new tool for self-myofascial release of the suboccipital muscles in patients with chronic non-specific neck pain: a randomized controlled trial. Spine (Phila Pa 1976) 2020;45(21):E1367-75.

20. Beardsley C, Škarabot J. Effects of self-myofascial release: a systematic review. J Bodyw Mov Ther 2015;19(4):747-58.

21. Kim KH, Kim SG, Hwangbo G. The effects of horse-riding simulator exercise and Kendall exercise on the forward head posture. J Phys Ther Sci 2015;27(4):1125-7.

22. Lee H, Chung H, Park S. The analysis of severity of forward head posture with observation and photographic method. J Korean Soc Phys Med 2015;10(3):9-17.

23. Park HK, Lee SY, Kim TH. The exception case about the diagnose forward head posture using the craniovertebra angle, craniorotation angle and Cobb angle: a case report. J Korean Soc Phys Med 2015;10(2):29-34.

24. Kim JY, Kwag KI. Clinical effects of deep cervical flexor muscle activation in patients with chronic neck pain. J Phys Ther Sci 2016;28(1):269-73.

25. Falla D, Jull G, Russell T, Vicenzino B, Hodges P. Effect of neck exercise on sitting posture in patients with chronic neck pain. Phys Ther 2007;87(4):408-17.

26. Storheim K, Bø K, Pederstad O, Jahnsen R. Intra-tester reproducibility of pressure biofeedback in measurement of transversus abdominis function. Physiother Res Int 2002;7(4):23949.

27. Mikesky AE, Bahamonde RE, Stanton K, Alvey T, Fitton T. Acute effects of The Stick on strength, power, and flexibility. J Strength Cond Res 2002;16(3):446-50.

28. Yoo WG, Yi CH, Cho SH, Jeon HS, Cynn HS, Choi HS. Effects of the height of ball-backrest on head and shoulder posture and trunk muscle activity in VDT workers. Ind Health 2008;46(3):289-97.

29. Salahzadeh Z, Maroufi N, Ahmadi A, Behtash H, Razmjoo A, Gohari M, et al. Assessment of forward head posture in females: observational and photogrammetry methods. J Back Musculoskelet Rehabil 2014;27(2):131-9.

30. Ruivo RM, Pezarat-Correia P, Carita AI. Intrarater and interrater reliability of photographic measurement of upper-body standing posture of adolescents. J Manipulative Physiol Ther 2015;38(1):74-80.

31. Jung S, Kwon O, Choi K, Ha S, Kim S, Jeon I, et al. Comparison of the thickness of the neck flexor muscles of subjects with and without a forward head posture on the two initial head positions during cranio-cervical flexion exercise. Phys Ther 
Korea 2015;22(4):44-50.

32. Jeon J, Ju S, Jeong H. The effect of cervical stabilizing exercises in the standing position and the supine position on deep neck muscle strength and endurance. J Phys Ther Sci 2012;24(5):423-5.

33. Ajimsha MS, Al-Mudahka NR, Al-Madzhar JA. Effectiveness of myofascial release: systematic review of randomized controlled trials. J Bodyw Mov Ther 2015;19(1):102-12.

34. Weppler $\mathrm{CH}$, Magnusson SP. Increasing muscle extensibility: a matter of increasing length or modifying sensation? Phys Ther 2010;90(3):438-49.

35. Bradbury-Squires DJ, Noftall JC, Sullivan KM, Behm DG, Power KE, Button DC. Roller-massager application to the quadriceps and knee-joint range of motion and neuromuscular efficiency during a lunge. J Athl Train 2015;50(2):133-40.

36. Jeong ED, Kim CY, Kim SM, Lee SJ, Kim HD. Short-term effects of the suboccipital muscle inhibition technique and craniocervical flexion exercise on hamstring flexibility, craniovertebral angle, and range of motion of the cervical spine in subjects with neck pain: a randomized controlled trial. J Back Musculoskelet Rehabil 2018;31(6):1025-34.

37. Monteiro ER, Cavanaugh MT, Frost DM, Novaes JD. Is selfmassage an effective joint range-of-motion strategy? A pilot study. J Bodyw Mov Ther 2017;21(1):223-6.

38. Halperin I, Aboodarda SJ, Button DC, Andersen LL, Behm DG. Roller massager improves range of motion of plantar flexor muscles without subsequent decreases in force parameters. Int J Sports Phys Ther 2014;9(1):92-102.
39. Grabow L, Young JD, Alcock LR, Quigley PJ, Byrne JM, Granacher U, et al. Higher quadriceps roller massage forces do not amplify range-of-motion increases nor impair strength and jump performance. J Strength Cond Res 2018;32(11):3059-69.

40. Healey KC, Hatfield DL, Blanpied P, Dorfman LR, Riebe D. The effects of myofascial release with foam rolling on performance. J Strength Cond Res 2014;28(1):61-8.

41. Drust B, Atkinson G, Gregson W, French D, Binningsley D. The effects of massage on intra muscular temperature in the vastus lateralis in humans. Int J Sports Med 2003;24(6):395-9.

42. Bron C, Dommerholt JD. Etiology of myofascial trigger points. Curr Pain Headache Rep 2012;16(5):439-44.

43. Rassier DE. Muscle biophysics: from molecules to cells. New York: Springer; 2010.

44. Watson DH, Trott PH. Cervical headache: an investigation of natural head posture and upper cervical flexor muscle performance. Cephalalgia 1993;13(4):272-84; discussion 232.

45. Ramezani E, Arab AM. The effect of suboccipital myofascial release technique on cervical muscle strength of patients with cervicogenic headache. PTJ 2017;7(1):19-28.

46. Salik Y, Ozcan A. Work-related musculoskeletal disorders: a survey of physical therapists in Izmir-Turkey. BMC Musculoskelet Disord 2004;5:27.

47. Adegoke BO, Akodu AK, Oyeyemi AL. Work-related musculoskeletal disorders among Nigerian physiotherapists. BMC Musculoskelet Disord 2008;9:112. 